\title{
Crustacean Cuticle: Synthesis and Remodeling of a Dynamic Extracellular Matrix During molt Cycle
}

\author{
Jasna Štrus ${ }^{1}$, Nada Žnidaršič ${ }^{1}$, Andrej Blejec ${ }^{1,2}$, Magda Tušek Žnidarič ${ }^{2}$ \\ 1 University of Ljubljana, Department of Biology, Ljubljana, Slovenia \\ 2 National Institute of Biology, Ljubljana, Slovenia
}

Cuticle is mostly considered as a nonliving part of crustacean body functioning as a mechanical and permeability barrier in different environments. In this contribution we want to expose the idea that cuticle is a living part of the animal body perforated by numerous pore channels with cytoplasmic extensions delivering various components to the newly synthesized extracellular matrix which is constantly remodeled during molt cycle. Terrestrial isopod crustaceans developed an elaborate cuticular matrix with different degree of calcification as an adaptation to various land habitats, ranging from sea shores to deserts.

Samples of surface cuticle were examined with transmission electron microscope in different molting stages of sea slaters Ligia palassii from Friday Harbor, WA, Ligia exotica from Wilmington, NC and Ligia italica from Piran Bay in Slovenia. Cytochemical localization of CaATPase [1] and EDX analysis was performed in cuticles at different molt stages.

Ultrastructural study of cuticles reveals a highly dynamic structure of epidermal cells which secrete cuticle during molt cycle [2]. In premolt animals epidermal cells change shape and cell polarity is established by apical extensions of long cytoplasmic processes and short microvilli (Fig.1). Chitin microfibrils are secreted at the tips of microvilli and exocytotic vesicles are present in between. Exocuticle is secreted as loosely arranged layers of branching chitinous fibers forming a fan-like pattern. Proteinaceous component of the cuticle is secreted from small vesicles which bud off the Golgi complexes in the apical part of epidermal cells (Fig.2). Calcification of cuticle starts already in the premolt and continues after exuviation. The localization of Ca ATPase activity in spherules and epidermis demonstrates intense calcium fluxes in tergal integument of intramolt animals. In intermolt animals lead deposits were present in the exocuticular pore canals, along the basolateral membranes in mitochondria and vesicles of epithelial cells [3]. The results of ultracytochemical reactions were confirmed by X-ray microanalysis of tissues in intramolt animals. The analysis of smaller spherules at the base of the old cuticle revealed the presence of calcium and phosphorous while no calcium was detected in larger spherules close to the new cuticle. Lead precipitates were detected in the spherules but not in the matrix of the ecdysal space. Extensive nanotubular structures of $25 \mathrm{~nm}$ diameter were observed in the ecdysal space of intramolt animals which interconnect the spherules and newly formed epicuticle (Fig.3). They contain electron dense material at the sites of attachment to the epicuticle. Immunocytochemical analysis of nanotubules did not confirm the presence of tubulin in the ecdysal space. Thicker fibers extend from hypodermis, cross the newly formed cuticle and are connected to spherules in the ecdysal space (Fig.4). They were described as massive arrays of fibers running from tendon cells through the new cuticle and ecdysal space up to the distal layers of the detached cuticle in adult premolt L. italica and in premolt intramarsupial specimens of P. scaber. [4].

Our results show that crustacean cuticle is a very dynamic extracellular matrix which is frequently renewed and constantly remodeled in terrestrial isopod crustaceans. Epidermal cells with their 
cytoplasmic processes extending through cuticular pore channels provide synthesized materials for the construction of the new cuticle. At the same time the materials resorbed from the old cuticle accumulate in the spherules of the ecdysal space with extensive nanotubular structures which are presumably involved in the formation of additional epicuticular layers [5].

\section{References:}

[1] Ando T, et al, Acta Histochem cytochem 14 (1981), p. 705.

[2] Štrus J and A Blejec In "Crustacean Issues 13", Eds. B.Kensley and R.C.Brusca, (A.A.Balkema Publishers, Rotterdam) p. 343

[3] Štrus J and P Compere (1996). Pflugers Arch - Eur J Physiol 431, p. 251

[4] Žnidaršič N et al, Zookeys 176 (2012), p.39.

[5] The authors acknowledge funding from the SRA and Short term visiting Scholarship in Friday Harbor Laboratories within UW-Ljubljana University Exchange Project, Grant ER176713.
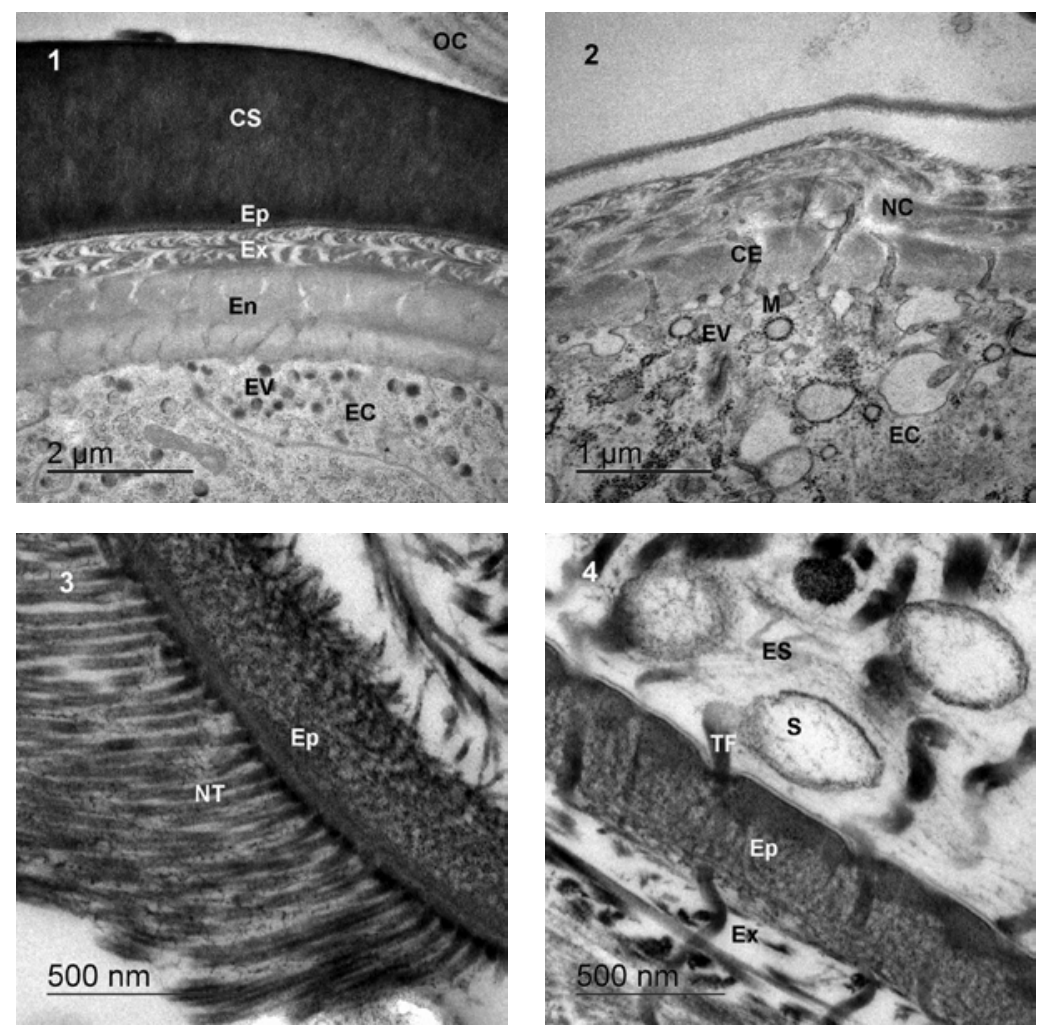

Fig. 1 Ligia italica in premolt stage: epithelial cell (EC) with exocytotic vesicles (EV) covered by a three-layered new cuticle (En-endocutiocle, Ex-exocuticle, Ep-epicuticle) and the old cuticle (OC) above cuticular scale (CS) is detached.

Fig.2. Ligia italica in premolt stage: Epithelial cells (EC) with microvilli (M), cytoplasmic extensions (CE) and exocytotic vesicles (EV) secrete components of the new cuticle (NC)

Fig.3 Ligia palassii in intramolt stage: nanotubular structures (NT) with electron dense tips at the surface of epicuticle (Ep)

Fig.4. Ligia palassii in intramolt stage: tendinous fibers (TF) extending through the exocuticle (Ex) and epicuticle (Ep) connecting to the spherules (S) in the ecdysal space (ES) 